\title{
GLOBALIZATION AND ITS ROLE IN THE DEVELOPMENT OF POST-SOVIET HIGHER EDUCATION INSTITUTIONS (ON THE EXAMPLE OF IVANE JAVAKHISHVILI TBILISI STATE UNIVERSITY)
}

\author{
Darejan Tvaltvadze \\ Irina Gvelesiani \\ Ivane
}

Javakhishvili Tbilisi State University, Georgia

\begin{abstract}
The impact of the various trends and challenges related to globalisation of higher education institutions and policies is profound, but also diverse, depending on the specific location in the global arena"(Damme, 2010). The given paper is dedicated to the study of globalizing processes and their influence on the development of Georgian Post-Soviet higher education area. The contemporary educational strategies are highlighted on the example of Ivane Javakhishvili Tbilisi State University - the leading educational institution of the whole Caucasus region. During the recent years Tbilisi State University underwent significant innovative processes comprising the following major directions: Internationalization establishment of foreign centers; implementation of joint projects and exchange programs; creation of international winter and summer schools; Modernization - implementation of 4level studies; creation of encyclopedic dictionary; restructuring faculties; redirection of scientific researches, etc. The significance of the above mentioned innovations, their impact on the development of Post-Soviet university life and Georgians' steps made towards the rapid integration into the European educational space - these are contemporary strategic issues and major challenges of our work. The highlighted strategies can serve as an exemplary and useful model of progress for those Post-Soviet universities of the world, which strive to join the European Higher Education Area.
\end{abstract}

Keywords: globalization; higher education; internationalization; modernization; Tbilisi State University.

\section{Introduction}

Nowadays, the area of higher education is facing a lot of new opportunities and challenges. All of them are stipulated by such factors, as globalization and market-determined processes. Increasing globalization breaks down all the barriers via "the "dédaublement du monde" (Reimann \& Zimmermann, 2008). On the one hand, it is seen as the "process, involving the deconstruction of space and state... the seat of profound tensions and contradictions" (Reimann \& Zimmermann, 2008). On the other hand, globalization drives "a revolution in the organization of work, the production of goods and services, relations among nations, and even local culture" (Carnoy, 2005). It has some important positive consequences with respect to cultural regeneration, communication, economic efficiency and the range of available products. Globalization refers to the 
increased consciousness of the world as a whole. Its new form can be observed as:

- An interconnected globe which is referred to as a "global village";

- The process which pushes people closer together through highly developed international trade and commerce, educational exchange, rapid transportation and communication;

- The erosion of national boundaries.

In the context of the "globalizing processes", higher education becomes a market-determined process and undergoes a tremendous expansion. Nowadays, more and more people are investing their time and money in acquiring an appropriate knowledge, because a skilled individual functions successfully in the global scale.

The given paper is dedicated to the study of the globalizing processes and their influence on the development of the Georgian higher education area. The contemporary educational strategies are highlighted on the example of Ivane Javakhishvili Tbilisi State University - the leading educational institution of the whole Caucasus region.

\section{Ivane Javakhishvili Tbilisi State University - recent developments and contemporary strategies}

Today's globalizing processes have so deeply rooted in the world of everyday life, that "modern society is quite fairly characterized as the society of risk and globalization. Extreme complexity of socialization process taking place under conditions of ongoing technological advances, urbanization, and capitalization in all fields of human activities shows the necessity of more active organization of social-cultural and social-pedagogical activity in all spheres of life..." (Sorochinskaya, 2011). Against this background, social-pedagogical activities undergo a tremendous expansion via involving all stages of knowledge-acquisition. Especial processes are observed on the level of higher education. They respond to varying social claims and create effective mechanisms for their fulfilment and implementation. The development of higher education has been corresponding to the major challenge of globalization - the world without borders and boundaries. The strive to the borderless world of knowledge stipulated the "emergence" of Bologna Process, which aimed at the creation of the entire educational space - European Higher Education Area (EHEA). The Bologna Process was named after the Bologna Declaration, which united 47 countries. Among them was Georgia - an ancient country which has been building a bridge between Europe and Asia and has been "walking" towards the global interconnectedness in almost all spheres of life. After joining the Bologna process Georgia has been successfully participating in the establishment of the European Higher Education Area. Nowadays, its higher 
education institutions are active members of international joint programs in different study and research fields.

The given work highlights the recent developments of Georgian higher education area via discussing the reforms carried out at Tbilisi State University.

Ivane Javakhishvili Tbilisi State University can be regarded as a driving force of the Georgian higher education. It was founded in 1918 by a western educated historian Ivane Javakhishvili. Tbilisi State University was the first educational body of this type not only in Georgia, but in the whole Caucasus region. Nowadays, the university maintains its old tradition - the implementation of western-oriented teaching strategies. As a forward looking institution it realizes that it faces new demands and strives to meet the challenges of the $21^{\text {st }}$ century by offering a top class education, developing research opportunities, enhancing its material-technical base and resources. The university's "main directions, principles, values and reforms are carried out dynamically in a systematic, coordinated manner and have placed Tbilisi State University on a development path leading towards a common world and European Higher Education Area" ("Profile of Ivane Javakhishvili Tbilisi State University").

After joining the Bologna process (in 2005) the following reforms have been carried out at the university:

1. The adoption of three cycles of higher education qualification:

- $\quad 1^{\text {st }}$ cycle - Bachelor's degree;

- $\quad 2^{\text {nd }}$ cycle - Master's degree;

- $\quad 3^{\text {rd }}$ cycle - Doctoral degree;

2. The establishment of European Credit Transfer and Accumulation System;

3. Intensive teaching of foreign languages;

4. Improvement of material-technical resources;

5. Building quality assurance and expert evaluation, etc.

However, nowadays, the major accent is put on the recent developments, which are directed towards the modernization and internationalization of the university.

Generally, "internationalization is defined as the variety of policies and programs that universities and governments implement to respond to globalization" ("Globalisation and Internationalisation of Higher Education"). It was invented and carried on in the late 1980s. However, during the last two decades new components were added to its multidimensional body: "moving from simple exchange of students to the big business of recruitment, and from activities impacting on an incredibly small elite group to a mass phenomenon" (Brandenburg \& Wit, 2011). It's a very important fact, that nowadays, the higher education of the world undergoes the tendency of shifting from the more cooperative model to the more competitive one. This tendency is filtered and shaped according to the internal context of each world university. However, the 
context may alter in accordance with the increased implementation of the "global/borderless education", which influences the national tendencies and gives them a new shape and purpose. The so-called "education across borders" considers the growing number of exchange students and academic staff. These "mobilities" foster the internationalization of universities.

Especially important internationalization strategies can be observed within the framework of the Bologna process, which fosters cooperation and competition. On the one hand, these activities ,emphasize that there should be more cooperation in order to develop a European area for higher education and research: „A Europe of Knowledge” ("Globalisation and Internationalisation of Higher Education"). On the other hand, there is a considerable emphasis on the argument, that this collaboration must face up the competition with nonEuropean countries.

Ivane Javakhishvili Tbilisi State University has been a part of the Bologna process and has accepted the great majority of its strategies. A special attention has been paid to the internationalization processes, which are split into two major dimensions: "local internationalization" ("internationalization at home") and "internationalization abroad". "Internationalization at home" considers such home university activities, as:

- researching activities;

- teaching and learning processes;

- curriculum and extra-curricular activities;

- the establishment of foreign centers (Center for Japanese Culture and Society, Yunus Emre Center of Turkish Culture, Language of Society, Center for Japanese Culture and Society, etc.) and their active participation in the teaching processes.

"Local internationalization" is usually regarded as a preparatory level, which strives to prepare the students for their integration into the global world of education. This movement from the local level to the international one i.e. from one dimension to the other is facilitated by:

- the establishment of close scientific and educational contacts with over hundred universities and centers of the world;

- $\quad$ the membership of several professional associations and networks (European University Association (EUA), Black Sea University Network (BSU), Agence Universitaire de la Francophonie (AUF), etc). This membership allows the university to enhance its administrative policies, to position itself as a strong player in the area of higher education and to reinforce academic or cultural ties;

- the establishment of international winter and summer schools, which raise multinational experience of students and improve their "marketability".

Nowadays, a special attention is paid to the implementation of annual summer and winter schools. In February 2014 Tbilisi State University (in 
cooperation with Goethe University Frankfurt am Main) established the Winter School "Digital Humanities - Kartvelology and Challenges of the $21^{\text {st }}$ Century". It aimed at the rising the 'network' society, "driven by technological innovation and the increasing strategic importance of information" (Damme, 2010). The Winter School gathered the students of different universities of Georgia. The Georgian and foreign prominent scholars got them acquainted with the technological facilities necessary for carrying out digital researches. The major accent was put on the importance of the utilization of OLAT (Online Learning and Training) - the most developed e-learning program, which is oriented on self-education, self-control and self-development. The greatest emphasis was put on the introduction of eLecture - a new format of teaching, which is based on the didactic scenario "electronic visualization of the taught material". All the above mentioned activates were directed towards the students' involvement into the world of technological innovations. It was planned, that after 2014 Winter Schools will have an annual character. They will aim at the acquisition of global skills. Moreover, digital researches will be implemented in different universities of Georgia. This fact will acquire the greatest significance. It will be one more step made towards the local internationalization of higher education institutions.

"Local internationalization" processes are usually accompanied by the "internationalization abroad", which comprises the growing number of international and mobility projects. During the recent years Tbilisi State University (TSU) "has been a beneficiary of almost 33 European Commission funded projects, namely TEMPUS, ERASMUS MUNDUS, FP7 and Jean Monet" ("Profile of Ivane Javakhishvili Tbilisi State University"). Nowadays, TSU is "a partner in 6 Erasmus Mundus... and around 19 running TEMPUS projects" ("Profile of Ivane Javakhishvili Tbilisi State University"), which are oriented on the support of educational reforms of some European countries.

One of the leading TEMPUS projects is DIMTEGU - "Development and Introduction of Multilingual Education Programs at Universities of Georgia and Ukraine". It is coordinated by the Faculty of Humanities of Tbilisi State University and comprises several EU and non-EU universities. DIMTEGU aims at supporting the multilingual educational reform in Georgia and Ukraine. It tries:

" 1 . To promote the reform and modernization of higher education in the partner countries;

2. To build up the capacity of higher education institutions in the partner countries and the EU, in particular for international cooperation and for a permanent modernization process, and to assist them in opening themselves up to society at large;

3. To enhance networking among higher education institutions and research institutions across the Partner Countries and EU Member States" (DIMTEGU). 
It's worth mentioning, that DIMTEGU meets the demands of Bologna Process via:

- $\quad$ applying modern pedagogical methods in MA programs;

- delivering modern MA and in-service teacher's certificate study programs in multilingual education;

- $\quad$ equipping the universities of Georgia and Ukraine with sufficient, up to date teaching materials and equipment;

- $\quad$ equipping libraries with computers and modern teaching materials in targeted universities to implement effectively BA and MA Teacher education programs in multilingual and international education, etc.

All the above mentioned strategies show the importance of DIMTEGU for the enhancement of globalizing processes at Ivane Javakhishvili Tbilisi State University. The contemporary internationalization activities are carried out "in tune with" the modernizing processes. However, generally, in Post-Soviet institution modernization or "making educational reforms is complicated: on the one hand the system is conservative, on the other hand education is obliged to change simultaneous to the developing world" (Grigoryan et al., 2010). Despite such contradictions, Tbilisi State University undergoes reformation processes. One of their preconditions is the restructurization of administrative and management systems, the creation of new governing units and the determination of their role in the life of the university. The recent and ongoing developments consider the following reforms:

1. The replacement of 3-cycle educational system with 4-cycle one - the acceptance of the fourth educational level (post-doctorate level) is the reflection of the direct influence of the European Higher Education Area;

2. Restructurization processes of the faculties, which are directed towards the perfect distribution of inner resources, potential capacities and student-oriented services;

3. The creation of the seventh faculty - The Faculty of Psychology and Educational Sciences. The existence of seven faculties is directed towards insuring more specialized teaching strategies;

4. The restructurization of the libraryand its enrichment with recent publications and databases. These processes are directed towards Georgian scientists' rapid integration into the European Scientific Area;

5. Redirection of scientific activities. In 2014 all the scientists of Tbilisi State University are required to publish their works in highly ranked journals - academic journals with impact factor. This is an innovative requirement (especially, for the representatives of the Faculty of Humanities), which will raise scholars' motivation and increase their integration into the European scientific society; 
6. Students' growing involvement in the governing processes of the university (nowadays, students are the members of the Representation Council, faculty councils and students' self-governments). These processes are directed towards the transparency of the governing activities.

All the above mentioned processes enhance the popularity of Tbilisi State University on the international level. Gradually, it is shifting from the more cooperative model to the more competitive one. As a result of this shift, Tbilisi State University takes part in the building of European Higher Education Area. Despite evident progress and prosperity, Tbilisi State University tries to increase the horizons of its activities and focuses on the following long-term objectives:

- $\quad$ "increasing the number of foreign instructed programmes;

- fostering cooperation with the existing partners;

- intensifying projects-related efforts;

- $\quad$ increasing the number of outgoing TSU students who have studied abroad;

- increasing the number of incoming students to TSU" ("Profile of Ivane Javakhishvili Tbilisi State University");

- implementing new, up-to-date specializations, which are of great demand especially in the employment-market;

- facilitating long-term relations with the international community via the implementation of innovative educational and cultural projects;

- carrying out intensive works for the creation of Multipurpose EnglishGeorgian Encyclopaedic Dictionary;

- $\quad$ carrying out an innovative plan of modernization of the university.

\section{Conclusions}

All the above mentioned enables us to conclude, that globalizing processes acquire the greatest importance in today's world. Significant changes are vividly seen in the educational systems of Post-Soviet universities, which undergo double reformation processes. On the one hand, they shift from socialistic to capitalistic ruling. On the other hand, they are trying to answer the demands of the contemporary globalized world via acquiring certain internationalizing and modernizing features.

The given paper highlights the reforms carried out at one of the most progressive Caucasian higher education institutions - Ivane Javakhishvili Tbilisi State University, which has presented exemplary results of progressive and dynamic development. During the recent years Tbilisi State University has shifted from the more cooperative model to the more competitive one. This process has been facilitated by the intensive implementation of internationalizing and modernizing innovative processes: establishment of foreign centers, implementation of joint projects and exchange programs, 
creation of international winter and summer schools, implementation of 4-level studies, restructuring faculties, redirection of scientific researches, etc. The highlighted strategies can serve as an exemplary and useful model of progress for those Post-Soviet universities of the world, which strive to join the European Higher Education Area. Focusing on the reforms of Tbilisi State University and sharing them will make other Post-Soviet institutions increasingly global in nature. They will acquire the ability to draw funding and research capabilities from around the world. These processes will significantly facilitate the final creation of the European Higher Education Area.

\section{References}

Brandenburg, U., Wit, H. (2011). The End of Internationalization.International Higher Educatio, 62, 15-17.

Carnoy, M. (2005). Globalization, educational trends and the open society.Education andOpen Society: A Critical Look at New Perspectives and Demands. Retrieved from:http://www.opensocietyfoundations.org/sites/default/files/carnoy_english.pdf

Damme, D. V. (2010). Higher education in the age of globalization: the need for a new regulatory framework for recognition, quality assurance and accreditation.Pendidikan dan Keilmuan. Retrieved from: http://pendidikan-keilmuan.blogspot. com/ 2010/03/higher-education-in-age-of.html

DIMTEGU. Retrieved from:http://dimtegu.tsu.ge/?lan=engl\&cat=y5Yjn

Globalisation and Internationalisation of Higher Education. In H. de Wit (Ed.)Revista de Universidad y Sociedad del Conocimiento, 2, 241-248. Retrieved from: http://openaccess.uoc.edu/webapps/o2/bitstream/10609/13540/2/v8n2-de-wit-eng.pdf

Grigoryan, V., Melkonyan, H., Greyan, L. (2010). Educational reform process and higher educational institution's (HEI) administration system modernization objectives in Gyumri State Redagogical Institute. Pedagogical technologies in socialization and resocialization of society, 1, 7-15.

Profile of Ivane Javakhishvili Tbilisi State University. Retrieved from: http://www.tsu.edu.ge/data/file_db/International/TSU\%20profile.2014.pdf

Sorochinskaya, E. (2011). Analysis of theoretical approaches to studying socialization process of modern children and teenagers." Pedagogical technologies in socialization and resocialization of society, 2, 74-83.

The Oxford handbook of comparative law. (2008). In: Reimann, M., Zimmermann, R. (Eds.) Oxford University Press. 